\title{
THE TREE-ROW-VOLUME SPRAYING SYSTEM AND ITS POTENTIAL USE IN NEW ZEALAND
}

\author{
D.W.L. MANKTELOW ${ }^{1}$ and J-P. PRAAT ${ }^{2}$ \\ ${ }^{1}$ HortResearch, Hawkes Bay Research Centre, Private Bag 1401, Havelock North \\ ${ }^{2}$ Agrichemical Group, Lincoln Technology, Private Bag 3062, Ruakura, Hamilton
}

\begin{abstract}
Tree canopy sizes and training systems can vary widely on modern apple orchards, but most growers do not have the information required to determine appropriate spray volumes and chemical rates for different canopies. Chemical rates and volumes currently used in the majority of New Zealand apple orchards are derived from an arbitrary standard application rate of 2,000 litres/ha. The Tree-Row-Volume(TRV) system for describing spray volume requirements on different canopies has been tested and widely adopted in America, but the American system appears not to work with New Zealand canopies and has not been adopted here. Development and validation of a modified TRV estimation system for use on New Zealand apples are described in this paper and potential benefits of TRV spraying are discussed.
\end{abstract}

Keywords: Tree-Row-Volume, TRV, spray application, spray volume, apple, canopy

\section{INTRODUCTION}

It is difficult to define agrichemical application rates required to achieve equivalent chemical doses and distributions and equivalent biological responses in crop canopies of different sizes and densities. Canopies with different surface areas and/or canopy volumes are likely to receive different average doses if sprayed at equivalent per hectare chemical rates.

The problem of matching chemical rates and sprayer outputs to different threedimensional crop canopies has been long recognised. Morgan (1964) addressed the problem by describing spray emissions in terms of canopy surface areas rather than ground areas. However, canopies also vary in depth and density and the American TreeRow-Volume (US-TRV) spraying system attempts to address these variables. The USTRV system was developed in response to uncertainties about dilute spray volume (and hence agrichemical rate) requirements on new apple plantings, with smaller than 'standard' tree forms. Buyerset al. (1971) proposed the US-TRV concept with reference to a 'standard' apple canopy, which has been widely accepted in the American literature to consist of trees about $6.1 \mathrm{~m}$ tall, $7.0 \mathrm{~m}$ wide, planted at $10.7 \mathrm{~m}$ row spacings. Successful pest and disease control has been achieved on such trees using dilute spray volumes of 3,740 litres/ha (400 US gallons/acre) and this was used as a 'base spray volume' for USTRV coverage estimates.

US-TRV spraying assumes that each cubic metre of Tree-Row-Volume (i.e. space down a row potentially occupied by canopy) will require a canopy density dependent volume of spray liquid to achieve a desired coverage. The US-TRV calculation assumes that a row of trees can be described as a rectangular box and the volume occupied by canopy per hectare is calculated on that basis (Fig. 1). The 'standard' apple canopy has a TRV of $39,900 \mathrm{~m}^{3} / \mathrm{ha}$ and use of 3,740 litres/ha on such trees suggested that one litre of dilute spray mixture would cover $10.7 \mathrm{~m}^{3}$ of canopy TRV to the point of runoff (Sutton and Unrath 1984). However, dense canopies and chemical thinner applications were found to require higher spray volumes (Herrera-Aguirre and Unrath 1980; Sutton and Unrath 1984; 1988). Spray coverage rates now promoted in North Carolina are for a base rate of $7.5 \mathrm{~m}^{3} \mathrm{TRV} /$ litre of dilute spray, with adjustments up to $10.7 \mathrm{~m}^{3}$ TRV/litre

Proc. 50th N.Z. Plant Protection Conf. 1997: 119-124 
according to a canopy density rating system (Sutton and Unrath 1984; 1988).

Sutton and Unrath (1988) examined spray deposits achieved in globular American canopies at different growth stages following application at rates based on coverage of $7.5 \mathrm{~m}^{3}$ US-TRV/litre. In the six canopies examined, US-TRV increase with growth between tight cluster and full leaf averaged $20 \%$ (range 2-36\%) and spray volumes were adjusted accordingly. They found that deposits at tight cluster were 1.2-2.0 times greater than deposits achieved on the same canopies at full leaf.

A system using a stage-of-growth-factor (SOGF) to make seasonal adjustments to TRV water rates has been promoted in New York state (Hoying et al. 1995). However, the SOGF system does not appear to have been rigorously tested and there are many situations when its use is not recommended (Hoying et al. 1995). In fact, Sutton and Unrath (1988) argued that early season sprays are critical for disease and pest control, so high early season deposits observed following TRV spraying should not regarded as justification for reducing pesticide rates at that time.

American apple tree forms have tended to be more globular than pyramidal and so fit rectangular row-end canopy profile assumptions reasonably well. However, some American advisors recommend that TRV calculations are made using actual canopy row end profiles in favour of basic rectangular profiles (Seeley 1991). A modified version of the US-TRV system has been adopted in Europe, whereby triangular row end profiles are measured from tree crown height and spread at half crown height (HC-TRV) (Fig. 1). Most European TRV spraying recommendations are estimated from concentrate, rather than dilute, base spray volumes and coverage estimates in the order of $20-50 \mathrm{~m}^{3} /$ litre of spray mix have been reported. Unfortunately there have been no authorative publications on TRV spraying in Europe and standard canopies and base spray volumes have not been well defined. It is therefore difficult to relate European TRV recommendations to New Zealand canopies.

The anticipated benefits of TRV spraying are identification of appropriate and consistent agrichemical rates and spray volumes for different apple tree sizes and training systems in order to provide equivalent pesticide doses on different canopies. On small canopies this may lead to agrichemical use reductions, while on larger canopies it should help ensure that sufficient agrichemical is applied to achieve the desired biological response.

The TRV system has been introduced to New Zealand before (Wilton 1990) and was discussed in the NZ Agrichemical Users' Code of Practice (Anon. 1995). However, TRV spraying has not been widely adopted in New Zealand because dilute spray application volumes estimated from the US-TRV system have usually been $\mathrm{ca}$. 70\% greater than those already used successfully by New Zealand growers. This paper describes an evaluation of the potential for TRV spraying in New Zealand.

\section{METHODS}

Thirty one apple canopies in the Waikato (16) and Hawkes Bay (15) districts were selected from a total of 15 orchards to represent the range of cultivar forms, tree sizes and training systems encountered in New Zealand apple production. Row spacing, tree height, height to first canopy, and canopy spread measurements at half metre height intervals were taken from two or three representative rows of each canopy. Measurements were made after harvest on trees in full leaf. All spread measurements were made at row ends by sighting along the rows. Each measurement was made to the nearest $0.1 \mathrm{~m}$ and aimed to include $>95 \%$ of the canopy (i.e. some protruding branches were ignored). These data were used to estimate US-TRV, HC-TRV and height-stratified-TRV (HSTRV) for each canopy; where HS-TRV was the sum of rectangular US-TRV measurements at half metre height intervals (Fig. 1).

Spray volume requirements for each canopy were estimated using the American $10.7 \mathrm{~m}^{3} \mathrm{TRV} /$ litre coverage figure for open canopies and this estimate was compared with the dilute spray volume usually applied to each canopy by the grower concerned.

The commercial practicality of TRV spraying was investigated on a Waikato orchard in the 1996-97 season. HS-TRV measurements were made from blocks representative of the range of canopy sizes on the orchard and five distinct HS-TRV classes were 


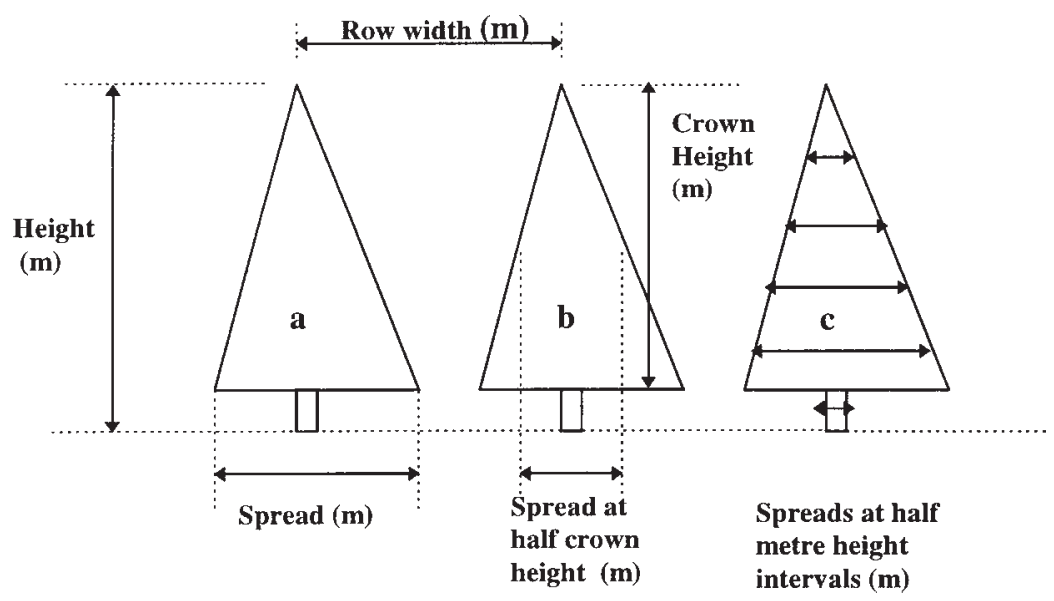

FIGURE 1: Measurements used in a) American (US-TRV), b) half crown height TRV (HC-TRV) and c) height stratified TRV (HS-TRV) estimates of Tree-Row-Volume, where:

$\operatorname{TRV}\left(\mathrm{m}^{3} / \mathrm{ha}\right)=$ Height X Spread X 10,000

Row Width

defined in approximately $4,000 \mathrm{~m}^{3} /$ ha bands. The largest HS-TRV was $32,000 \mathrm{~m}^{3} /$ ha for 20 year old centre leader Granny Smith trees, with other canopy volumes ranging from 27,200 down to $13,400 \mathrm{~m}^{3} /$ ha. The whole orchard was normally sprayed at ' 2 times concentrate' at 1,000 litres/ha, using chemical rates derived from a base dilute volume of 2,000 litres/ha. Given that acceptable pest and disease control had apparently been achieved at these rates in the largest trees, it was estimated that coverage of $16 \mathrm{~m}^{3} /$ litre at 2000 litres $/ \mathrm{ha}^{3}$ was appropriate on this orchard (i.e. $32,000 \mathrm{~m}^{3} / \mathrm{haHS}$-TRV divided by 2,000 litres/ha). Orchard blocks were selected from each of the five size ranges and sprayed using HS-TRV water volumes from 16 October until harvest. A standard axial fan orchard airblast sprayer was calibrated to deliver five application volumes. The calibration was achieved by fitting rotary nozzle bodies (Spraying Systems) to the sprayer outlet manifold. Each nozzle body held five TX nozzles (Spraying Systems) and application volumes were altered by nozzle selection, rather than travel speed or pressure adjustments. All sprays were applied at ' 2 times concentrate', with HS-TRV spray volumes between blocks ranging from 1000 to 420 litres/ha. Active ingredient concentration in the spray tank was held constant for each spray mixture, so smaller canopies received lower per hectare agrichemical rates than were normally used on the orchard (e.g. $42 \%$ of normal dose on the smallest canopy sprayed at 420 litres/ha). Because spraying began after the start of the growing season, pest and disease assessments were made only to evaluate whether commercially acceptable control had been achieved. A pair of Red Chief blocks were sprayed at either 470 litres/ha (HS-TRV volume estimate) or 1,000 litres/ha (as normally used on the orchard) and pest and disease control at harvest was evaluated by a local consultant following N.Z. Integrated Fruit Production sampling protocols. Pest and disease levels at harvest in the other blocks were evaluated by the grower.

\section{Tree-Row-Volume measurement systems}

\section{RESULTS AND DISCUSSION}

The HS-TRV measurements were on average $59 \%$ and $75 \%$ of the US-TRV and HC-TRV measurements respectively (Fig. 2). The New Zealand canopies examined tended more towards pyramidal rather than rectangular row-end profiles, which accounted 
for the better match with triangular HC-TRV estimates than the US-TRV estimates. However, the wide range of canopy row-end profiles observed suggested that some attempt to measure true canopy profile would be preferable to simply placing all canopies into either rectangular or triangular categories. Row-end profiles for HS-TRV estimates took longer to measure than the other two systems and involved a more complex calculation. However, additional measurement time was small compared with the preparation time prior to measurement and the calculations were easily handled using a simple computer programme or paper work sheet. It was considered that HS-TRV measurements could be undertaken by suitably trained growers or consultants.

Spray volumes used versus TRV estimates of volumes required

The dilute spray volumes used at full leaf in the 31 surveyed apple canopies are

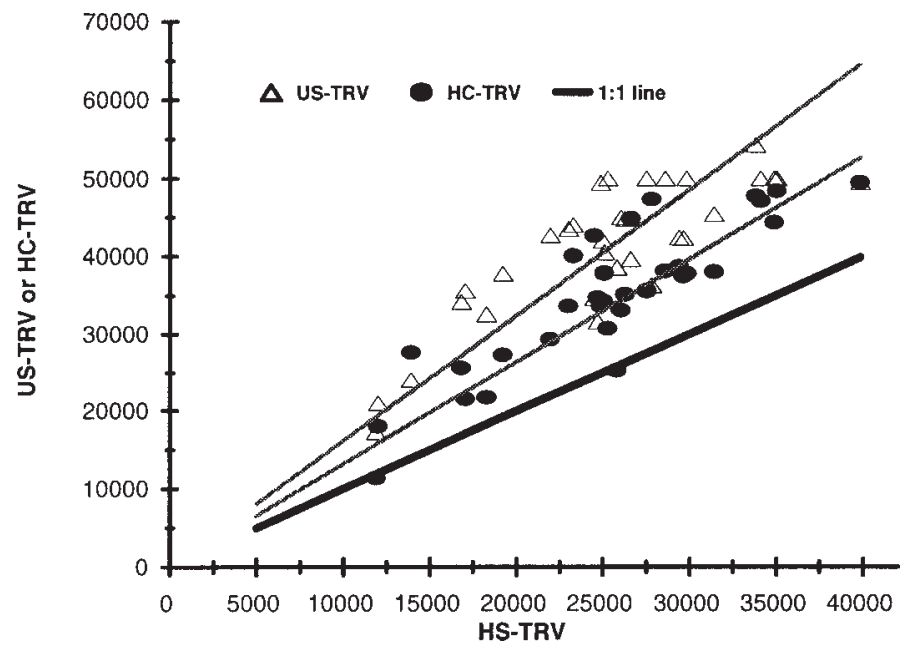

FIGURE 2: Comparison of HS-TRV measurements with US-TRV and HV-TRV estimates.

shown in Fig. 3 against estimated spray volume required using $10.7 \mathrm{~m}^{3} /$ litre coverage for HS-TRV. The majority of spray applications used dilute volumes from 2000-2200 litres/ ha (or the concentrate equivalent of these). The $10.7 \mathrm{~m}^{3} /$ litre coverage figure was arbitrary and was used in the absence of actual coverage measured under New Zealand conditions. The growers surveyed appeared to have made little attempt to match spray application volumes to different canopy sizes. Pest and disease control on all of the orchards examined was generally considered acceptable by the growers concerned. Given that canopies over 23,000 $\mathrm{m}^{3} \mathrm{HS}$-TRV were sprayed using volumes well below requirement estimates (Fig. 3), a spray coverage factor greater than $10.7 \mathrm{~m}^{3} /$ litre may well prove appropriate for New Zealand conditions. This is supported by the trial carried out on the Waikato orchard, where a coverage factor of $16 \mathrm{~m}^{3} /$ litre was estimated. Black spot, powdery mildew and pest control on all of the HS-TRV sprayed blocks on that orchard were considered commercially acceptable and equivalent by both the grower and consultant assessments.

While encouraging, the results reported in this paper cannot be treated as a full validation of HS-TRV estimates of spray volume requirements. Further work is needed to account for variations in canopy density and to allow better definition of spray coverage factors appropriate to different New Zealand canopies. Most importantly, pest and disease management achieved from TRV spraying needs to be assessed in replicated 
experiments over several seasons.

\section{CONCLUSION}

The TRV system appears to have potential to help New Zealand apple growers

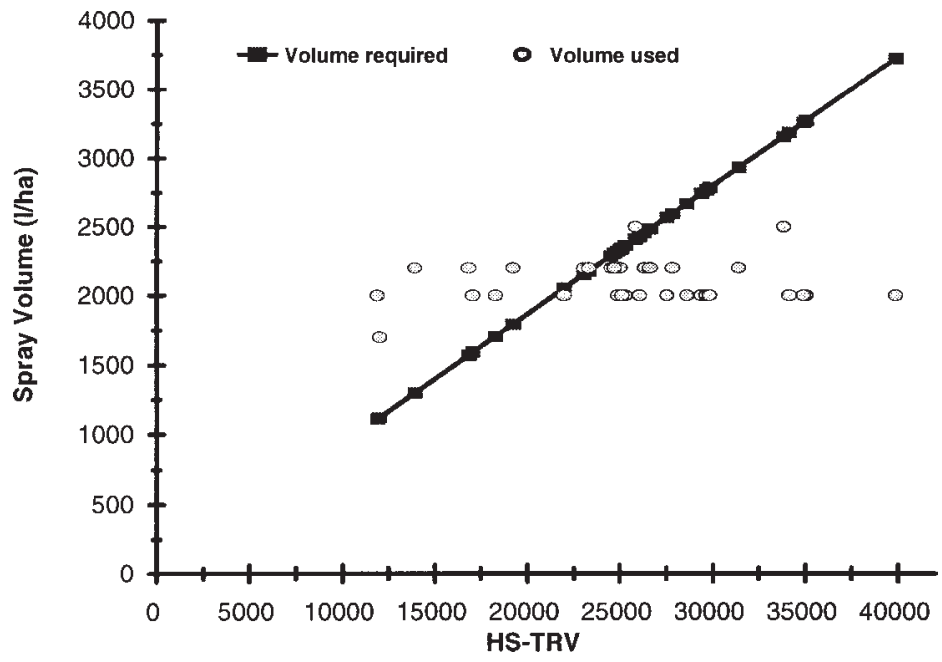

FIGURE 3: Dilute spray volumes at full leaf used on surveyed orchards versus estimated spray volumes required (assuming coverage $=10.7 \mathrm{~m}^{3} \mathrm{HS}$ TRV/litre).

estimate spray volume requirements for different sized trees. The HS-TRV system represents a substantial improvement over the US-TRV or HC-TRV systems, because HS-TRV measurements provide more representative estimates of actual canopy rowend profiles. However, further validation of the HS-TRV system is required, particularly with respect to volume adjustments in relation to canopy density adjustments and better definition of spray coverage factors appropriate for New Zealand canopies.

\section{ACKNOWLEDGEMENTS}

Thanks to the Foundation for Research, Science and Technology and ENZA Fruit for funding part of this work. Also thanks to the management of Sunfruit Orchards, Hamilton for facilitating the on-orchard evaluation of TRV spraying.

\section{REFERENCES}

Anon. 1994. Guidelines for integrated production of pome fruits in Europe. IOBC Technical Guideline III. Second edition.

Buyers, R.E., Hickey, K.D. and Hill, C.H., 1971. Base gallonage per acre.Virginia Fruit 60: $19-23$.

Herrera-Aguirre, E. and Unrath, C.R., 1980. Chemical thinning response of 'Delicious' apples to volume of applied water. HortScience 15(1): 43-44.

Hoying, S.A., DeMarree, A.M., Breth, D.I. and Silsby, K.J., 1995. Fruit Notes. Cornell Cooperative Extension. Letter No: 7.3pp.

Morgan, N.G., 1964. Gallons per acre of sprayed area: an alternative standard term for spraying plantations. World Crops, June: 64-65.

Seeley, E.J., 1991. Limiting fruit pesticide usage is worthy of consideration. Good Fruit Grower, May 1: 7-9. 
Sutton, T.B. and Unrath, C.R., 1984. Evaluation of the Tree-Row-Volume concept with density adjustments in relation to spray deposits in apple orchards. Plant Disease 68(6): 480-484.

Sutton, T.B. and Unrath, C.R., 1988. Evaluation of the Tree-Row-Volume model for full-season pesticide applications to apples. Plant Disease 72(7): 630-632.

Wilton, J., 1990. Spray application - the weakest link in fruit thinning and pest and disease control. The Orchardist, July: 27-28. 